Sociedades Precapitalistas, vol. 7, nº 2, e026, junio 2018. ISSN 2250-5121 Universidad Nacional de La Plata.

Facultad de Humanidades y Ciencias de la Educación.

Centro de Estudios de Sociedades Precapitalistas (CESP)

\title{
Organización campesina y dominios políticos en la cuenca del Duero altomedieval
}

Iñaki Martín Viso

Universidad de Salamanca, España

viso@usal.es

Cita sugerida: Martín Viso, I. (2018). Organización campesina y dominios políticos en la cuenca del Duero altomedieval. Sociedades Precapitalistas, 7(2), e026. https://doi.org/10.24215/22505121e026 


\section{Organización campesina y dominios políticos en la cuenca del Duero altomedieval}

Peasant organization and polities in the Early Medieval Duero's Basin

Iñaki Martín Viso

Universidad de Salamanca, España

viso@usal.es

\section{Resumen:}

El texto recoge la conferencia presentada en las IV Jornadas de Jóvenes Investigadores sobre Sociedades Precapitalistas. El objetivo es ofrecer una imagen panorámica de cómo las diferentes estructuras políticas que se implantaron entre los siglos V al X en la cuenca del Duero influyeron en la organización de las comunidades campesinas. Aunque estas disfrutaron de una considerable agencia social, política y económica, el tributo y el control de los espacios de uso comunal facilitaron la intervención de elites relacionadas con el poder estatal, con la excepción del periodo de colapso que se abrió en los siglos VIII y IX.

Palabras Clave: Comunidades rurales, Estructuras políticas, Tributo, Comunales, Península Ibérica.

\section{Abstract:}

The article is based on the paper presented to the IV Conference of Young Scholars about Precapitalist Societies. It is a general view about how the different polities which were implemented in the Duero's basin between the 5th and 10th centuries influenced the way that rural communities were organized. Although rural communities enjoyed a great social, political and economic agency, the taxes and the control of commons make the intervention of elites linked to the central authority easy, with the exception of the collapse in 8th an 9th centuries.

KEYWORDS: Rural communities, Polities, Taxes, Commons, Iberian Peninsula.

\section{Organización CAMPEsina Y DOMinios políticos EN LA CUENCA Del Duero ALTOMEDIEVAL *}

Cuando la profesora y buena amiga Rosana Vasallo me invitó a participar en estas IV Jornadas de Jóvenes Investigadores sobre las Sociedades Precapitalistas con una conferencia, y me informó del tema de las jornadas, "Prácticas políticas y formas de subordinación", consideré oportuno aprovechar la ocasión para ofrecer un panorama que abarcase varias épocas y situaciones. Se trataba de eludir un análisis excesivamente parcial, que, a pesar de su interés, quizá no 'permitiera construir un discurso más amplio sobre los procesos que intervinieron en la compleja relación entre sociedades campesinas y dominios políticos en la Alta Edad Media en la cuenca del Duero, que es mi campo de observación. Ahora bien, ese panorama está construido con retazos incompletos de casos locales, ya que la evidencia empírica de la que disponemos es fragmentaria y esporádica. Una situación bien conocida en lo que se refiere al registro escrito, limitado a unos pocos documentos, a la epigrafía y a las colecciones legislativa y canónica del periodo visigodo que, sin embargo, ofrecen serias dificultades para utilizarlas fuera del contexto de un discurso político proveniente del círculo del poder central y cuya aplicación a los ámbitos locales genera dudas. Por otro lado, la elaboración de un registro arqueológico de calidad sobre la cuenca del Duero, esos $90000 \mathrm{kms} 2$ que componen la submeseta norte, está todavía por hacer, aunque se han realizado valiosos avances en las últimas décadas, de manera que resulta imposible elaborar un relato sobre esos fenómenos sin tomar en consideración la información arqueológica. 
El ámbito cronológico elegido es deliberadamente extenso, por lo que no pretende ser exhaustivo. Pero tiene una característica común: la menor presencia -e incluso ausencia- de poderes centrales efectivamente operativos a escala local y de manera homogénea por todo el territorio. De alguna forma, mi conferencia busca dar una respuesta (no la respuesta) al problema de la presencia de estructuras estatales débiles o a procesos de construcción estatal a través de un caso regional concreto. En primer lugar, me centraré en los siglos $\mathrm{V}$ a VII, que constituyen el primer segmento de mi análisis. En primer lugar, es necesario plantearse cómo funcionaban las formaciones políticas postimperiales. Dentro de ellas, existía un foco central en torno a los monarcas, que ejercían una actividad de patronazgo, aunque a una escala muy inferior a la de los emperadores tardorromanos, y se elaboraban una serie de lazos políticos que tenían como discurso la etnia. En cambio, las sociedades locales disponían de una mayor autonomía. Como señala Halsall, los reinos solo se podían mantener unidos si la gente se identificaba con ellos en las localidades y esto únicamente sucedía en función de las ventajas que ofrecía esa identificación. En estas condiciones, las estructuras políticas altomedievales se muestran como estados "delgados", con una escasa capacidad de intervención en los ámbitos locales -salvo casos muy concretos, como los longobardos en el siglo VIII. La consecuencia es que las sociedades locales disfrutaban de una mayor capacidad de actuación y su integración en estructuras políticas superiores incluía unas fuertes dosis de negociación.

Ese fue el caso de la cuenca del Duero, una zona, por otro lado, alejada de los focos políticos más destacados A mediados del siglo $\mathrm{V}$, la cuenca del Duero se hallaba fuera del control romano, sin que se hubiera formado un nuevo y estable dominio político centralizado. Aunque los suevos se habían instalado en el Noroeste y pretendieron construir un poder hegemónico sobre Hispania, su derrota en la batalla de Astorga de 456 ante los visigodos foederati del emperador Avito, frustró cualquier posibilidad al respecto. Si el reino suevo sobrevivió, a pesar de morir su rey y perder su tesoro, fue a causa del desinterés del rey visigodo Teodorico por controlar efectivamente el territorio del Noroeste peninsular, debido a que sus bases de dominio estaban en el sur de la Galia y a que Avito rápidamente fue depuesto por Ricimero, quien colocó en el trono imperial a Mayorino. Pero también intervino la ausencia de poderes sólidos que pudieran competir por la hegemonía política. Aunque el reino suevo dominase teóricamente algunas zonas de la meseta encuadradas en las antiguas provincias de Gallaecia y Lusitania, de los escasísimos datos de los que disponemos parece inferirse que se trataba de un poder con una escasa presencia directa en el ámbito local. El eje político estaba constituido por su capital, Braga, y a lo sumo incorporaba algún otro centro, como Tude y Porto, lugares donde se manifestaba su poder. Fuera de estos lugares, existía una amplia red de entidades locales. A pesar de que pudiera reivindicar un territorio político más o menos extenso, que en los mapas aparece como una mancha homogénea, en la práctica los nexos con las sociedades locales del Noroeste eran endebles. Puede decirse que el reino suevo constituía una estructura muy delgada sustentada por la ausencia de cualquier otro núcleo de poder central.

El poder visigodo en la cuenca del Duero se construyó a partir de estas coordenadas. La construcción de la hegemonía visigoda sobre la península ibérica comenzó a fraguarse tras el final de la influencia ostrogoda a mediados del siglo VI. A partir de ese momento, el núcleo de poder visigodo fue haciendo efectiva su autoridad, en especial durante el reinado de Leovigildo. Esta situación se dejó sentir en la cuenca del Duero, una zona que hasta entonces no estaba sujeta en la práctica a ninguna autoridad central, pero que en esos momentos, y mediante expedientes diversos, se integró dentro del sistema político toledano.

La crónica de Juan de Bíclaro expone sucintamente este proceso, subrayando el papel de las campañas militares, en especial sobre cántabros (cuya capital, Amaya, era uno de esos asentamientos rurales fortificados emplazados en la cuenca del Duero) y suevos, que permitieron la conquista y legitimaron el nuevo dominio. Pero también fueron víctimas de esa expansión algunos poderes locales, como los sappos, probablemente una población asentada en el valle del río Sabor, actualmente en Portugal, a la que se le aplicó una etiqueta con la que se pretendía definir a un conjunto político en el que no emergía con claridad una jefatura. También el Biclarense registró la campaña contra los montes Aregenses - posiblemente la zona montañosa entre Astorga y Orense- donde fue capturado un tal Aspidius, senior loci (señor del lugar o local), junto con su esposa e 
hijos, adueñándose de sus bienes y tierras. En este caso, parece existir una clara jerarquía, aunque no estaba asociada a un territorio claro. En ambos casos se trataba de poderes que no estaban dentro de la égida de una autoridad central sino que se localizaban en el amplio sector que se extendía desde el núcleo de poder suevo hasta las áreas bajo dominio visigodo (Bicl., VII, 5; VIII, 2; IX, 2).

Esta situación de una compleja red de poderes locales se plasma con claridad en el denominado Parrochiale Sueuuorum (PS). Se trata de un texto integrado en las actas del II concilio de Lugo y redactado en torno al año 572; en él, se recogen las diferentes sedes que se encontraban dentro del espacio suevo, así como una serie de parroquias dependientes (David, 1947). Como ha puesto de manifiesto Pablo de la Cruz Díaz, el elenco corresponde a una serie de unidades políticas locales menores, cuya sujeción al poder suevo se habría llevado a cabo en estos momentos gracias al uso de la administración eclesiástica facilitada por la conversión al catolicismo de los monarcas de Braga. Posiblemente el número de esas entidades era mayor del que aquí se señala, puesto que no todas las sociedades locales se relacionaban a través de este expediente. Lo llamativo es que, junto a las sedes episcopales, urbanas, aparece una pléyade de lugares menores como parroquias: Sanabria, Zamora, Coyanza... Una comparación de los lugares citados con las cecas documentadas en el primer momento visigodo - es decir hasta la concentración de la acuñación en unas pocas cecas llevada a cabo por Recesvinto a mediados del siglo VII- permite resaltar cómo hay una tendencia a que parroquias y cecas coincidan, aunque hay excepciones. La conclusión es que el nuevo poder visigodo reconoció la existencia de esas unidades menores, donde posiblemente subsistían jefaturas locales que habían surgido tras el final del dominio romano. Por tanto, junto a la conquista de algunos territorios -bien por las resistencias de ciertos poderes locales o bien como estrategia para amedrentar y cercenar cualquier atisbo de resistencia posterior-, se produjo una negociación, que facilitó la integración de las entidades existentes, que pudieron mantener sus mecanismos de organización interna, a cambio del reconocimiento de la autoridad toledana. La propia existencia de cecas sería una muestra de cómo se implementaron esas relaciones: si la moneda de oro -aquella que se acuñó en estas cecas- era inicialmente un medio destinado a la tributación, su acuñación pudo deberse a las necesidades de hacer frente a los tributos, que llegaban a los reyes en forma de tremises. El bajo número de cecas podría ser a su vez una muestra de que esa tributación no tenía un nivel muy elevado. Además, y quizá de una manera mucho más notoria, la acuñación implicaba también el reconocimiento de la autoridad que podía emitir moneda.

Un aspecto importante es que muchos de esos lugares desde los cuales parece articularse el poder local eran asentamientos rurales fortificados. La información de la que disponemos sigue siendo escasa y compleja, pero las últimas investigaciones -y muy especialmente el trabajo realizado sobre el yacimiento de El Castillón, que podría ser la parroquia de Maurellos Superiores et Inferiores del PS- señalan un momento de configuración a partir del siglo V. Se trata de asentamientos muy diversos, que recientemente Juan Antonio Quirós consideraba como "castillos de primera generación". La presencia de cerámicas de mayor calidad, la existencia de importantes centros artesanales y metalúrgicos y la calidad y la relativa complejidad de sus estructuras defensivas parecen ser indicios de su vinculación con grupos aristocráticos que podían movilizar una mano de obra y que tenían acceso a determinadas redes de distribución. Es significativa además la presencia de rituales funerarios asociados a la deposición de ciertos ajuares, que podrían ser un indicio de prácticas culturales específicas y relacionadas con la construcción de un nuevo horizonte político.

Siguiendo con la tipología de Juan Antonio Quirós, en el caso de la cuenca del Duero, nos encontramos tanto con grandes recintos que posiblemente surjan en zonas donde el declive de las ciudades es temprano y profundo (como Peña Amaya, Mave o La Morterona, que debe identificarse con el centro de Saldania); pero también con lugares de dimensiones menores, entre 2 y 10 has, que se sitúan en las zonas periféricas de los territorios urbanos en áreas donde las ciudades sobrevivieron. Un buen ejemplo de ello sería el caso del suroeste de la cuenca del Duero, donde, junto a las ciudades de Salamanca o Ávila, aparecen diversos núcleos de estas características: Salvatierra de Tormes, La Cabeza de Navasangil, Lerilla, Yecla la Vieja... Estos asentamientos rurales fortificados no configuraron un sistema defensivo de profundidad. Su localización 
obedecía más bien al control de franjas territoriales comarcales, de pasos ganaderos o fluviales destacados. La extremada variabilidad de sus construcciones parece ir en contra de un diseño por parte de un agente común. Mi hipótesis es que estos asentamientos eran los centros de poder de aristocracias de cuño regional o comarcal, que ejercían un dominio sobre determinados ámbitos geográficos concretos. No sería el único expediente en este contexto, pero creo que sí uno de los más generalizados.

Cuando el poder visigodo se implantó definitivamente sobre la cuenca del Duero lo hizo sobre una geografía política plagada de estos asentamientos rurales fortificados. Eran los "lugares centrales" de la cuenca del Duero, los nuevos puntos sobre los que se vertebraba una abigarrada jerarquización territorial. Volviendo al Parrochiale Sueuum, parece que algunos de los lugares allí citados coinciden precisamente con estos lugares, como Coyanza o Bergido. Sin embargo, hay problemas a la hora de constatar su ocupación desde un punto de vista arqueológico más allá del siglo VI. En buena medida, la menor visibilidad del registro arqueológico de este periodo, ante la ausencia de materiales cerámicos diagnósticos, puede ser la causa, ya que tenemos evidencias de la permanencia en la ocupación de algunos de esos lugares (como Tintinolho o Bergido). Pero el estudio de los materiales de otros centros parece indicar un abandono a finales del siglo VI, coincidiendo en el tiempo con la afirmación del poder visigodo, como ocurre en El Castillón o en La Cabeza de Navasangil. Es probable que las respuestas al nuevo dominio visigodo fueran muy diversas y que no debamos plantear un modelo único de comportamiento: algunos sobrevivieron, quizá con una serie de transformaciones que de momento no observamos, mientras otros pudieron abandonarse, bien por una actuación violenta o, sobre todo, porque se modificaron parcialmente los patrones de actuación política. Ahora bien, esto no obsta para considerar que el poder visigodo se construyó sobre la base de la negociación y el pacto con los poderes locales establecidos en el valle del Duero, dada la ausencia de referencias a resistencias en la mayoría del territorio. La consecuencia fue que el regnum visigodo en el siglo VII en la cuenca del Duero se manifestaba a través de esas elites locales, que eran agentes del poder toledano y miembros destacados de unas sociedades locales a las que pertenecían.

Una pizarra escrita parece evidenciar ese statu quo. Se trata de un pleito que enfrentaba a Basilio y Lolus por el intercambio de unos caballos, en el que Lolus se vio obligado a prestar juramento ante unos vicarios y unos jueces. Llama la atención que en el texto no se citen en ningún momento ni al comes ni al thiufadus como fuentes de delegación de poder, a pesar de reconocerse expresamente la autoridad del monarca, en este caso Recaredo, en la data del documento (Velázquez Soriano, 2004, n 39). Por tanto, jueces y vicarios actuaban sin la intervención de poderes superiores vinculados a la autoridad central y su legitimidad se sustentaba principalmente en una preeminencia reconocida en un ámbito local.

Este texto nos acerca a un corpus de enorme interés como son las llamadas pizarras visigodas. Se trata de inscripciones realizadas sobre lajas de pizarra, con contenidos muy diversos. El corpus puede subdividirse en tres grandes conjuntos, atendiendo a su contenido. Por un lado, tendríamos las pizarras con textos escritos, que corresponden a una documentación privada de muy diversa índole: compraventas, pleitos, pagos posiblemente fiscales... Se trata del conjunto más conocido y estudiado, debido a su enorme interés. Por otro lado, disponemos de pizarras con signos numéricos, que son las más frecuentemente recuperadas, aunque generalmente solo se han conservado fragmentos de piezas mayores. Su dispersión es bastante mayor, ya que mientras las pizarras con texto tienen una geografía muy específica (sur de Salamanca, oeste de Ávila, norte de Cáceres), las pizarras numerales se han podido documentar en numerosas zonas, aunque la mayor concentración procede del suroeste de la meseta del Duero. Por último, nos encontramos con piezas que tienen representaciones, dibujos en ocasiones difíciles de comprender. En realidad, como puede fácilmente desprenderse, nos encontramos con un conjunto muy dispar, unificado exclusivamente por el uso de un mismo soporte de escritura.

Las pizarras numerales ofrecen, a pesar de sus dificultades de interpretación, algunas claves relevantes. Aunque en general solo se han podido recuperar pequeños fragmentos, cuando se han conservado pizarras completas, como sucede en El Cortinal de San Juan (Salvatierra de Tormes, Salamanca), se puede observar 
que estamos ante piezas de gran tamaño, con medidas superiores al medio metro de largo. Se componen de líneas independientes, en cada una de las cuales hay distintas combinaciones de números, que, sumados, dan una cantidad que se repite en cada línea, aunque esa cantidad varía en cada pizarra. En el caso de algunas de las pizarras de El Cortinal de San Juan las líneas se cierran y se abre un nuevo campo separado. Parece que estamos ante un sistema que facilita la multiplicación de unidades homogéneas, que no precisan su identificación (es decir se cuenta siempre lo mismo en cada pieza). Se trata de un sistema que se ha podido evidenciar en otras partes del Mediterráneo occidental, como es el caso de las Tablillas Albertini, del Norte de África, datadas a finales del siglo V. Debe entenderse como una contabilidad inmediata, con aquello que se cuenta delante de los ojos, y que sirve para elaborar otro documento más preciso. Por esa razón, se utilizaba un material de escritura sub-estándar, mientras que el documento definitivo podía realizarse en otro soporte. En el caso del interior de la península ibérica, hay evidencias del uso de pizarras con este sistema matemático en época tardorromana, siempre en relación con villae. Puede inferirse que era una práctica asociada quizá a la contabilidad doméstica en estos entornos. A partir del siglo $V$, esas pizarras aparecen en los nuevos espacios elitistas.

Una vía para comprender la funcionalidad de estas pizarras numerales es analizarlas dentro de sus contextos arqueológicos. Un dato relevante es que las mayores concentraciones de pizarras numerales proceden de algunos de los asentamientos rurales fortificados situados en el suroeste de la cuenca del Duero. Es el caso ya citado de El Cortinal de San Juan, pero también de Lerilla -de donde proceden unos 900 fragmentos- y de La Cabeza de Navasangil. En otros casos, como Yecla la Vieja, el número de pizarras es escaso, aunque también se han hallado en diversas intervenciones. No son el único lugar donde aparecen: conocemos hallazgos en contextos urbanos, especialmente en Ávila, aunque no se ha podido todavía recuperar un alto número de pizarras. Las pizarras numerales aparecen también en elevada cantidad en algunos lugares relacionados con actividades productivas (aceite, metalurgia), como Monte el Alcaide o La Legoriza, en las serranías salmantinas. Por otra parte, los hallazgos de estas piezas se vinculan a derrumbes y a silos, es decir no formaban parte de un archivo sino que era un material ya desechado. En tal sentido, las grandes concentraciones de pizarras numerales deben entenderse como los materiales desechados de una oficina contable. Se trataría de una serie de anotaciones realizadas sobre unidades que estaban a la vista de quien hacía la contabilidad, y con una función inmediata. Es interesante observar cómo en estos lugares las pizarras con textos son muy escasas y responden siempre al mismo modelo: se trata de listados de antropónimos asociados a unidades de algo no identificado. Es muy probable que sea una variable de las pizarras numerales, anotando en este caso el nombre de los pagadores.

Estas oficinas contables estaban situadas en algunos asentamientos rurales fortificados, así como en espacios relacionados con una producción de cierta complejidad. Pero ¿qué se estaba contando? Puede sernos útil el caso de una pizarra procedente de Santibáñez de la Sierra (Salamanca). En la parte superior se conservan doce líneas con numerales, algunas de las cuales están completas y suman 26 , mientras que en la parte inferior, y separada por una línea horizontal, aparece un breve texto: [[s]]Gratus fecit urbat /qui lesserit pedat [ium?] / in soca boina. La frase parece indicar la existencia de un peaje (pedatium) que gravaría algún tipo de uso de una zona para el ganado bovino y, si pudiera relacionarse con los numerales, éstos reflejarían la contabilidad que se estaba llevando a cabo (Velázquez Soriano, 2004: $\mathrm{n}^{\circ} 2$ ). Las anotaciones numéricas se vincularían con la contabilidad de ese peaje, un aspecto que coincide con el emplazamiento de Santibáñez, en un paso de la Sierra de Francia, una zona con una fuerte relevancia ganadera en este periodo, a tenor de lo que reflejan los datos palinológicos.

Esta pista resulta útil para entender otros casos. El estudio de la amplia colección de pizarras numerales halladas en el pago de El Cortinal de San Juan (Salvatierra de Tormes, Salamanca) sugiere una situación semejante. En una de las pizarras, se ha podido identificar la representación de un barco, que podría relacionarse con aquello que se estaba contando en esa oficina contable. Dado que El Cortinal de San Juan se encuentra en un paso tradicional del río Tormes, junto a un puente (hasta que a mediados del siglo pasado el 
embalse de Santa Teresa alteró considerablemente el paisaje), se ha planteado la hipótesis de que estuviéramos ante una contabilidad asociada a un peaje fluvial. En Lerilla, el lugar que mayor número de fragmentos de pizarras numerales nos ha proporcionado, algunas de las pizarras tienen representaciones de animales, que podrían indicar una contabilidad vinculada al control del paso del ganado por este sector, una situación semejante a la que se comprobaba en Santibáñez de la Sierra. En ambos casos, las oficinas contables se sitúan en asentamientos rurales fortificados, probablemente controlados por elites locales. Serían la evidencia de una captura del excedente in situ mediante mecanismos que podemos calificar como "políticos": las elites locales ejercían su dominio sobre las comunidades gracias a que disponían de la legitimidad o del poder para exigir determinados pagos y controlar pasos relevantes. Es probable que estemos ante la herencia de prerrogativas del poder político en una escala local en época tardorromana, que fueron reutilizadas por las elites locales en el momento en el que el horizonte imperial se desvaneció.

De todos modos, pueden existir otras posibilidades. Así, en el caso de las oficinas contables asociadas a centros productivos, como Monte el Alcaide o La Legoriza, podrían ser el resultado del control sobre procesos productivos. De especial interés es el caso de Monte el Alcaide, donde se encontraron las pizarras junto a una pileta de unos 26 litros de capacidad, por lo que su presencia podría relacionarse con aquello que se estaba depositando en dicha pileta. El hecho de que por los alrededores aparezcan varias lagaretas hace pensar en una producción cercana, que se centralizaba en este punto, quizá relacionada con el aceite. La cuestión es saber quién dominaba esa producción; en mi opinión, podría ser un control dominical, ante la necesidad de tener personal capaz de contar y de hacerlo de manera continua. Pero no necesariamente estaríamos ante un gran propietario como ante individuos que disfrutaban de una propiedad relevante a escala local.

Por tanto, las grandes concentraciones de pizarras numerales estarían asociadas a oficinas contables. Las situadas en los asentamientos rurales fortificados serían el indicio del control de procesos productivos externos mediante recursos "políticos", derivados del papel asumido por las elites locales en este periodo. Las que se encuentran en lugares relacionados con la producción podrían ser un indicio del control dominical de esa producción. En cualquier caso, serían el indicio de una captación in situ del excedente por parte de elites.

Pero últimamente se han recuperado algunos fragmentos de pizarras numerales en asentamientos rurales campesinos. Tal es el caso de La Cárcava de la Peladera, cerca de Segovia, de donde proceden un par de pequeños fragmentos de pizarras numerales. Otro caso es el del poblado de Las Henrrenes, en Cillán (Ávila), donde se han hallado varios fragmentos de pizarras numéricas. Muy distinto es el caso de las pizarras encontradas en el poblado de Lancha del Trigo (Diego Álvaro, Ávila), donde las piezas, en este caso escritas, formaban parte del material constructivo de las estructuras domésticas, por lo que fueron reaprovechadas en un momento posterior.El mejor ejemplo es el yacimiento de La Genestosa, en Casillas de Flores, en el extremo suroccidental de la provincia de Salamanca, donde hemos llevado a cabo cuatro campañas de excavación. Este lugar parece estructurarse en el periodo posromano a través de pequeños asentamientos concentrados situados junto al arroyo del Mazo de Prado Álvaro, pero respetando el área inundable y más fértil, y asociándose a tumbas excavadas en la roca. Las intervenciones realizadas sobre uno de ellos, El Cañaveral, ha arrojado información sobre una ocupación domésticaposromana, datada entre finales del siglo $\mathrm{V}$ y mediados del siglo VII, un área habitacional que se relaciona con la actividad de unos pobladores campesinos que expresaban las diferencias internas sobre todo mediante el registro funerario, con tumbas excavadas en roca. Allí se han podido recuperar 8 pequeños fragmentos de pizarras numerales (provenientes casi con seguridad de 3 piezas distintas) en 2 derrumbes. Pero ¿por qué aparecen estas pizarras en contextos campesinos?

Un aspecto relevante es el escaso número de fragmentos recuperados: no estamos ante las grandes concentraciones, que definían a las oficinas contables emplazadas en los asentamientos rurales fortificados. Su presencia se relacionaría, en cambio, con la existencia de conexiones entre el mundo campesino y las elites que precisan de esa contabilidad. Podría ser un indicio del pago de algún tipo de tributo o de la captura del excedente generado en ese asentamiento, por lo que la pizarra sería el vestigio de una anotación llevada a cabo 
en el momento de esa captura. En tal sentido, sería una prueba de las relaciones entre un mundo campesino, que no tendría por qué ser completamente autónomo, y las elites que parecen controlar algunos "lugares centrales". Por otra parte, la ausencia de elementos que permitan identificar pautas de consumo diferenciadas o elementos asociados a la presencia de elites, permite plantear que la producción estaba bajo el control de las familias residentes en ese poblado. Todo ello aboga por un control que podríamos calificar como "externo" o "político", que llevaría a la punción (bien en forma de renta o de impuesto) sobre los excedentes de esas familias, aunque quizá de manera muy puntual

Esta explicación puede plantearse a partir de algunos casos localizados en el suroeste de la meseta. La cuestión, de momento irresoluble, es saber si esta situación puede extrapolarse a otros ámbitos de la cuenca del Duero. La región del Bierzo destaca por ser el escenario geográfico de una serie de escritos de carácter hagiográfico, que proporcionan interesantes datos sobre la relación de esta zona relativamente periférica con el centro de poder. Una de esas hagiografías es la Vita Fructuosi, narra cómo Fructuoso acompañó a su padre, que ostentaba el cargo de $d u x$, a las montañas y valles del territorio bergidense a fin de requerir rationes de los rebaños, para lo cual llevó a cabo un registro y discutió con los pastores sobre esas rationes (Díaz y Díaz, 1974). La semántica fiscal del pasaje permite interpretarlo como una muestra de una fiscalidad centrada en la ganadería. Una hipótesis factible es que tales pastores fueran realmente la aristocracia de la zona, es decir los potentes locales, individuos con intereses ganaderos y propietarios de rebaños. En tal caso, la intervención del poder central estaba claramente mediatizada por estos potentes que eran los que realmente disponían de la capacidad de recaudar el tributo en el ámbito local.

Otro conjunto de informaciones proviene de los escritos autobiográficos de Valerio del Bierzo, un eremita de finales del siglo VII que dejó por escrito sus peripecias, con el objetivo de presentarse a sí mismo como un auténtico "hombre santo"(Díaz y Díaz, 2006). Los protagonistas de la sociedad local en los escritos autobiográficos de Valerio, además de los monjes y eremitas, son algunos potentes que acogían a los anteriores. Por desgracia, no hay una información clara de cómo se implementaba su dominio social. Es verdad que individuos como Ricimero controlaban propiedades de cierto tamaño, aunque el pagus de Ebronanto podría ser en realidad una circunscripción local y no una propiedad en sentido estricto. Sea como fuere, lo que Valerio pone de relieve es que a la altura de finales del siglo VII un mecanismo de obtención de prestigio en un ámbito local era el patrocinio en la construcción de iglesias y en la protección de determinados santones de influencia local. No parece, en cambio, que hubiera una gran propiedad en el sentido más habitual: Ricimero sin duda era un gran propietario en la escala berciana, pero su dominio se sustentaba en otras bases y es posible que entre ellas estuviera la captación tributaria, lo que explicaría su caída en desgracia con el rey.

Este modelo se quebró en el siglo VIII, cuando la invasión musulmana colapsó al reino visigodo, sin que se implementase en la cuenca del Duero un nuevo sistema de poder centralizado. Resulta muy complicado reconstruir la situación de la cuenca del Duero entre el siglo VIII y la segunda mitad del IX, cuando se llevó a cabo la expansión territorial asturiana.Ese proceso se ha entendido en términos de "repoblación", partiendo de la hipótesis de que en el siglo VIII la cuenca del Duero sufrió una intensa despoblación. Sin embargo, esa idea debe ser descartada, pues no es más que una imagen creada desde el poder astur para legitimar lo que fue simplemente una expansión política. Se ha propuesto, en cambio, una disminución demográfica, que fue progresivamente suplida por la llegada espontánea de campesinos procedentes del norte peninsular; la repoblación sería exclusivamente el acto de control político efectuado posteriormente por la autoridad regia. Sin embargo, creo que esta explicación -basada en el estudio toponímico- tampoco sirve. Me parece más factible pensar que en el siglo VIII en la cuenca del Duero se produjo un colapso del sistema político, pero las comunidades campesinas no desaparecieron, aunque cabe pensar que hubo algún tipo de transformación. De hecho, buena parte de los asentamientos rurales fortificados parecen haber sido abandonados, aunque la información es todavía demasiado parca.

Una revisión de los datos existentes permite situar la experiencia duriense en este periodo en el marco analítico de los colapsos sociopolíticos, caracterizados por una reducción brusca de la complejidad, que afectó 
sobre todo a los elementos más relacionados con las elites y el estado: la inversión monumental, el comercio a gran escala, la presencia de una vida urbana, la circulación monetaria... Ahora bien, los datos palinológicos ponen de manifiesto cómo en zonas como las serranías del Sistema Central se mantuvo la actividad antrópica, aunque descendió la intensidad de la deforestación en las áreas más elevadas, quizá como consecuencia de la disminución de la presión elitista sobre los campesinos. También hay algunas evidencias, todavía escasas, sobre la permanencia de asentamientos aldeanos en el valle del Duero, como es el caso de La Huesa, Las Henrrenes o Canto Blanco, en las inmediaciones de Sahagún. E incluso se observa cómo en este periodo aparecieron nuevos asentamientos que tomaron como ejes ciertas construcciones eclesiásticas, como ocurrió en Santa María de la Aldea (Baltanás, Palencia) a finales del siglo VIII o comienzos del siglo IX. Poco podemos todavía decir acerca de cómo se estructuraban estas comunidades y cuáles eran sus jerarquías internas. Pero la lectura de algunas informaciones posteriores revela cuál podía ser el contenido del dominio social en este periodo.

En 904, el presbítero Gratón donó al infante y diácono Gonzalo, hijo de Alfonso III, todos los bienes que poseía en el territorio del castro de Monzón, incluyendo la iglesia de Santa María, que él había restaurado, así como una serie de sernas que tenía en otros lugares como Karelias, Quintana Mediana, en Campo, y el castro de Cisneros (Sáez, 1987: doc. 17). El texto señala la presencia de un poder local representado por el presbítero Gratón, que actuaba en este sector de la cuenca del Duero, y que, mediante esta donación, se vinculaba con la monarquía asturleonesa. No creo que estemos ante una donación como resultado de la instalación de Gratón dentro de los mecanismos de implementación del poder asturleonés, pues nada de ello se menciona en el documento, a pesar de que, de ser así, habría sido muy relevante. En cambio, hay que pensar en un poder preexistente, emplazado en una zona de la meseta donde no hay evidencia alguna de una intervención directa de los monarcas. La condición clerical del personaje parece interesante para descubrir cuáles podían ser los medios de construcción y legitimación del estatus personal en un momento anterior a la integración en la estructura política asturleonesa. Por otro lado, la composición de los bienes que dona Gratón -y que quizá le fueran devueltos como consecuencia de la donación- describe lo que eran los mecanismos de dominio sociopolítico en el valle del Duero antes de la llegada de los asturianos: territorios que incorporaban lugares defensivos (castros) y en los que se poseían iglesias y sernas.

Para las comunidades campesinas un elemento relevante eran los comunales. Se trataba de uno de los componentes básicos de la identidad comunitaria, no solo por la existencia de una reserva para la producción sobre todo ganadera, sino también porque el acceso a ellos marcaba la pertenencia o no a dicha comunidad. Estos espacios se convertían en el escenario de unas prácticas colectivas gestionadas por ese mismo colectivo, generándose de esa manera una identidad comunitaria. Uno de los mecanismos de afirmación de un poder aristocrático sobre el conjunto de la comunidad -aunque no el único- debió ser el control de los derechos de acceso a esos comunales, no tanto mediante la gestión directa como a través de una autoridad superior que salvaguardaba el buen uso y la defensa de dichos espacios comunales y, por ende, de las prácticas colectivas.Ese debió seruna de las vías fundamentales de la construccióndel poder de la monarquía asturleonesa en la cuenca del Duero en los siglos IX y X.

En este sentido, resulta llamativo el papel de iglesias y sernas. Las primeras eran espacios con un notable significado simbólico. De momento no se han hecho avances significativos desde el punto de vista arqueológico para determinar las fases altomedievales - mal denominadas prerrománicas- de las construcciones eclesiásticas en la meseta del Duero, salvo cuando se dispone de evidencias monumentales. Pero en ese caso, estaríamos ante iglesias patrocinadas sobre todo por el poder asturleonés o por los grupos aristocráticos pertenecientes a ese círculo. En cambio, poco se sabe desde un punto de vista material de las iglesias erigidas por elites locales o comunidades, un aspecto sobre el que, en cambio, tenemos cierta información para el País Vasco y Galicia. Es probable que una parte muy importante de esas iglesias se levantaran como parte de un esfuerzo común, aunque con un reparto desigual de las cargas, que pudo beneficiar a ciertos notables locales, auténticos patronos de las iglesias. Esto explicaría la proliferación de 
estas iglesias en buena parte del valle del Duero -aunque no en todas sus comarcas- y el hecho de que en determinadas zonas se conservase todavía a la altura del siglo XII una propiedad comunitaria de las iglesias, que llegó incluso a la Baja Edad Media. En esos casos, funcionaban como auténticos bienes comunales. También funcionaban como centros de asamblea donde los vecinos se reunían para celebrar pleitos o ratificar acuerdos.

En cuanto a las sernas, el término, como es bien sabido, tiene varias acepciones. En los siglos XII y XIII, se refería a una prestación de trabajo obligatorio. Sin embargo, en el periodo altomedieval se identificaba con un espacio agroganadero de dominio colectivo de una comunidad, aunque en su interior podían existir subdivisiones trabajadas por familias individuales. Se trataba de un bien comunal, aunque su dominio superior -no necesariamente la gestión cotidiana- podría estar en manos de elites o instituciones. Aunque se ha propuesto que fueran consecuencia de procesos de colonización agraria en este periodo y que tuvieran una localización periférica, recientes análisis revelan la centralidad espacial de las sernas dentro de la configuración del terrazgo. A finales del siglo IX y comienzos del X, las sernas aparecen en manos de magnates, aunque un análisis más específico pone de relieve cómo hubo un traspaso desde el dominio regio, como parte del patronazgo monárquico que alimentaba a las redes sociopolíticas. Llama la atención cómo en estos primeros compases del proceso de integración política, muchas de las sernas de la zona oriental de la Meseta del Duero se relacionaban con ciertos castros o "lugares centrales", como también sucede en la donación del presbítero Gratón. Parece una hipótesis razonable pensar que desde esos lugares se articulaba un dominio basado en el control de tales espacios colectivos, lo que conformaba una parte relevante del estatus de las elites durienses.Posiblemente cada uno de esos espacios articulaba varias sernas, como ocurre con los casos de Sublancio o Dueñas, lo que posibilitaba un tipo de poder comarcal que afectaba directamente a las comunidades locales. Cuando los territorios de la Meseta del Duero fueron integrados en el reino asturiano, los reyes y magnates se esforzaron por asumir el control de un mecanismo clave en el dominio sobre las comunidades.

El avance del reino astur y la integración de territorios hasta entonces habitados y organizados, pero ajenos a la autoridad política centralizada, se llevó a cabo con la decisiva aportación de grupos aristocráticos. Aunque las crónicas, originadas en el ambiente de la corte de Oviedo, describan el proceso como una iniciativa puramente regia, la realidad fue mucho más compleja y parece que determinados personajes, a los que se concede un título condal, que es más un reconocimiento de su autoridad que una delegación de funciones regias, actuaron con gran autonomía y posteriormente pudieron utilizar el poder regio como un paraguas legitimador. En el caso de la cuenca del Duero oriental, es decir el Condado de Castilla, el proceso parece haber sido diferente. Aquí las noticias hablan de varios individuos revestidos con el título de conde que se hacen con el control político de diversos puntos entre finales del IX y principios del X. La explicación que puede darse es una configuración endógena de poderes cada vez más activos, que competían entre sí por la hegemonía, utilizando para ello el recurso del dominio sobre puntos políticamente relevantes (activos o no) del territorio y situándose teóricamente bajo la égida de los reyes asturianos, si bien en la práctica eran autónomos con respecto a este. Su título condal es de nuevo un reconocimiento de una autoridad "de facto" y no de una delegación de poder. El resultado fue que en torno a 930 emergió un poder unificado en la figura del conde Fernán González, dependiente en teoría del rey de León, pero en la práctica con gran autonomía.

La narrativa oficial de las crónicas muestra el proceso como una sucesión de intervenciones de los reyes, únicos protagonistas. Cuesta pensar en esos términos, y más bien parece que debamos hablar de acuerdos tácitos con las poblaciones y elites, de construcción de determinados "lugares de poder" que servirían como focos desde los que se haría patente la nueva autoridad y también de resistencias. Estas han dejado un pálido reflejo en las fuentes escritas; un texto de 909 menciona cómo Alfonso III tuvo que hacer frente a una gente barbarica en el lugar de Alkamín, cerca de Tordesillas, y que tuvo que enviar allí a sus tropas para quebrar esa resistencia. Estas tierras son posteriormente entregadas a dos clérigos (Mínguez, 1976: doc. 9). El objetivo es la formación de una nueva autoridad, lo que conlleva, sin embargo, la necesidad de obtener el control de 
bienes o tierras; estas se pueden redistribuir y sobre todo se construye un dominio sobre ellas (control de derechos de acceso y/o pago de rentas).

Por otro lado, la imagen que nos transmite la narrativa oficial es la de un proceso homogéneo y controlado por el rey, pero no fue necesariamente así.Un texto datado en 878 y procedente de Astorga es altamente revelador (Cavero Domínguez y Martín López, 1999: doc. 5). Se trata del pleito que enfrenta a los hijos de Catelino con el obispo de Astorga Indisclo sobre la propiedad de una villa - una propiedad fundiariaen Brimeda, cerca de Astorga. El documento es de enorme interés porque la populatio de Astorga aparece ejecutada por el conde Gatón, en tiempos del rey Ordoño I, (en 854) aunque este no es un agente activo: fue directamente el conde Gatón con el populus del Bierzo - probablemente miembros de la elite regional que formaban una suerte de entourage militar- quien llevó a cabo esa integración bajo el paraguas del poder de Ordoño I, del que sólo se dice que la acción se emprendió en su tiempo. La mención a Gatón como conde reflejaría más bien el resultado de esta acción: el reconocimiento de su autoridad, que le hace ser juez en esta disputa. Ahora bien, no quiero dejar pasar por alto que la integración política del espacio astorgano conllevó la creación de unidades fundiarias en manos de los recién llegados. De hecho, la villa objeto del pleito era un bien que se disputaban dos "repobladores"; a ello se añade que entre los límites consta una villa de Gaton, que puede relacionarse con el conde homónimo. La cuestión es saber cuál es el significado del término villa. El obispo Indisclo dice que él mandó indicar los límites de la villa y la puso en explotación edificando casas y cortes, arando y sembrando, así como haciendo entrar a su ganado. Quizá fueran áreas hasta entonces vacías, pero se hallaban emplazadas en el seno de un espacio que estaba explotado y ordenado, donde se introduce un nuevo elemento patrimonial, calificado como villa.

La construcción de esas parcelas, quizá en terrenos que no estaban específicamente destinados a labores agrarias o a pastos, modificó el agrosistema existente. El mecanismo legal que legitimaba ese dominio fue el scalido o la presura. Ambos términos deben entenderse como ficciones jurídicas que permitían un control superior (no necesariamente directo) sobre bienes y personas, sin necesidad de que se construyesen nuevos espacios agrarios. En algunos casos, es el rey quien legitima esas apropiaciones, marcando sus límites, como sucede en el caso de los bustos (es decir espacios destinados al pasto) que habían roturado los abuelos y padres de Fredisando en Eslonza y cuya propiedad provenía de un acto de escalido, cuyos límites habían sido determinados por el infante Gonzalo, hijo de Alfonso III (Ruiz Asencio y Ruiz Albi, 2007: doc. 24). Una situación que no debía ser muy diferente de la que deja traslucirse en la donación en 918 de unas tierras por parte de Ordoño II a favor del monasterio de Santiago de Valdevimbre, que habían sido ocupadas por el rey en los conflictos políticos de finales del reinado de su padre Alfonso III, y que este anteriormente ya había entregado al monasterio con sus límites, según los había delimitado Abaiub iben Tevite (Sáez, 1987: doc. 45). Resulta interesante advertir cómo tales bienes se encontraban "in Paramo, Busto", de nuevo un espacio destinado al pasto. Pero no solo se detectan esos bustos, sino que los espacios apropiados pueden asociarse a la construcción de iglesias. Así ocurre en Boada, cerca de Roa, en Castilla, donde Diego Rodániz controlaba la iglesia de San Andrés y un espacio adyacente, tal y como había sido delimitado por el conde Nuño Núñez a comienzos del siglo X (Serrano, 1925: doc. XIV).

Todo ello no quiere decir que los derechos de presura o de squalido provengan exclusivamente de los reyes. Son numerosos los textos en los que se habla de presuras sin que pueda identificarse con claridad la acción directa de los reyes. Sin embargo, esta opción, posiblemente al alcance de pocos individuos e instituciones, reforzaba los derechos. Así se desprende de algunos casos en los que la presura es anterior a la legitimación real, como ocurre con el lugar de Rioseco, ocupado por Cixila, obispo de León y fundador de Santos Cosme y Damián de Abeliar, y que posteriormente en 911 fue donado por el rey García (Sáez, 1987: doc. 99). Por otra parte, no todos los bienes que se obtienen como presura no son necesariamente espacios agroganaderos, pues hay constancia, por ejemplo, de torres.

En realidad, los monarcas asturleoneses podían realizar esa cesión de bienes gracias a que, a través de los mecanismos de integración política, se habían convertido en poseedores de un dominio político superior que 
incluía a gentes y tierras. Muestra de ello es la donación que realiza Alfonso IV en 928 a favor del monasterio de Santos Cosme y Damián de Abeliar de la villa situada en Fonte Incalata, en el valle de Covillas, añadiendo que los hombres que la habitasen estarían sujetos a la autoridad del obispo y deberían pagarle un canon anual, lo que posiblemente refleje cuál era la expresión real del poder monárquico en ese punto (Sáez, 1987: doc. 79).No obstante, este tipo de situaciones, en las que la autoridad política concede bienes y derechos en forma de villas, o sanciona presuras, se circunscriben a áreas muy concretas, sobre las cuales el poder directo de los reyes es bastante sólido, como es el caso del entorno de la ciudad de León. Sin embargo, en otras zonas de su dominio, los reyes no eran capaces de llevar a cabo una política de esas características, debido a que la implementación del nuevo dominio político se basó más en acuerdos tácitos con las poblaciones existentes, y no mediante la presencia directa del rey.

De todos modos, el objetivo que se perseguía no era la obtención de numerosos recursos fundiarios; de hecho, no parece que los reyes dispusieran de ese tipo de bienes sino más bien de un dominio superior sobre los mismos. La función principal era el establecimiento de unas "políticas de la tierra" que situasen al rey como un gran agente redistribuidor de bienes y derechos en favor de determinados individuos e instituciones. En la medida en que esto sucediese, el rey podía articular una red política en su beneficio. No obstante, podrían surgir problemas por el hecho de que la potestad superior regia sobre las comunidades era en realidad tácita y posiblemente transaccional, y no tan homogénea como aparece en las fuentes escritas. Así lo revela una vista judicial celebrada en 931 ante Alfonso IV, en relación con la propiedad de los lugares de Manzaneda y Garrafe que se disputaban los monjes del monasterio de San Julián de Ruiforco y los habitantes de dichos núcleos. Los monjes habían recibido de Alfonso III esos lugares, pero los habitantes reclamaban sus derechos argumentando que estaban en su término porque los habían roturado mediante presura (Sáez, 1987: doc. 89). Las razones esgrimidas por los habitantes son de gran interés, al recurrir a la formación de nuevos espacios agroganaderos a través de la presura, sin que medie intervención regia. El resultado fue que el monarca ordenó delimitar los términos que pertenecían al monasterio. Parece que de esta forma se definía aquello que el rey había podido ceder, que no era todo el territorio ni todos los derechos, sino una parte de ellos, quizás áreas previamente de uso comunal, lo que provocó que los habitantes roturasen nuevas áreas.

Esto nos lleva de nuevo al control del acceso a los comunales por parte de los reyes como mecanismo de consolidación del dominio político. La aceptación o imposición del poder asturleonés debió favorecer que los monarcas se hicieran con esos derechos como sus garantes y, por tanto, máximas autoridades de las comunidades. Así sucedió con las sernas, que permitían definir al nuevo poder regio o magnaticio como un poder local, sustentado en el control de mecanismos básicos de la actividad comunitaria a esa escala. En zonas donde no se había producido una integración política en forma de "lugares centrales" controlados por reyes o condes, es probable que el control de espacios comunales fuera una herramienta eficaz para la afirmación del poder. Un ejemplo sería la cesión de la dehesa comunal (es decir del control sobre su acceso) de los habitantes del alfoz de Los Ausines, cerca de Burgos, a cambio de no tener que desempeñar labores de castillería en 972 (Fernández Flórez y Serna Serna, 2017: doc. 2). Aunque en otros casos, esa autoridad sobre los espacios comunales no derivó necesariamente en una apropiación por el conde de Castilla, sino su defensa (y, por tanto, su reconocimiento como autoridad suprema por esas comunidades supralocales), como sucedió en el área de Alfania en 1014 (Zabalza Duque, 1998: doc. 75).

Este control de los comunales pudo servir también para la redistribución de derechos a fin de crear redes, sobre todo mediante la formación de entidades que estuvieran ligadas estrechamente con los reyes. Así ocurrió con algunos monasterios, que fueron auténticos arietes del poder monárquico en estas zonas y que recibieron determinados derechos, una situación que en ocasiones derivó en conflictos con los campesinos. Un buen ejemplo es lo que sucede en el monte de Pardomino, un área de la montaña leonesa, en el alto curso del río Porma. En 917, el rey Ordoño II entregó a unos confessores (es decir unos monjes) llamados Trasmundo y Recesvindo el lugar de San Andrés, según lo habían obtenido los abades Fredemundo y Máximo, a fin de que construyeran allí un monasterio. El objetivo del rey era la formación de una institución que quedase 
ligada a su red. Para ello, le concedía un territorio de monte, sobre el que previamente el monarca debe haber disfrutado de algún tipo de derecho (Sáez, 1987: doc. 41). Apenas 8 años más tarde, en 925, Fruela II confirmó al abad Atanarico el lugar donde estaba el monasterio y añade la serna de Uilla Donica (Sáez, 1987: doc. 68). Resulta interesante la donación de la serna, que debe entenderse como un espacio agrario sobre el que se ejerce un derecho superior, probablemente un bien de uso comunal. El topónimo es llamativo por cuanto se identifica la serna con una villa, es decir una unidad de gestión de la propiedad aristocrática, que estaba en manos del rey, es decir del domnus y de ahí el apelativo de Donica. No se estaba concediendo un bien distinto sino que se pretendía definir qué tipo de dominio se traspasaba. Ordoño II había concedido un término al monasterio de San Andrés; una vez erigido, Fruela II especifica que esos términos componen una serna.Esta interpretación permite comprender mejor el pleito resuelto en 944. El antiguo obispo de León Frunimio y los fratres eremitas de Pardominos denunciaron ante el rey que los habitantes de los lugares de Campolongo (posiblemente Campillo), Estavillo, Ferreras, Vulterario (Reyero?), Vegamián, Lodares y Noantica entraban en los términos del monasteriopara arar, hacer pacer sus ganados y talar. Como consecuencia de ello, y por orden de Ramiro II, una serie de magnates laicos y eclesiásticos realizaron una delimitación, señalando que la zona desde Peña de San Pedro (Castrum Petrosum) hacia occidente sería territorio de los habitantes de dichos lugares, aunque no podrían ni arar ni poner molinos, y hacia oriente se convertía en espacio bajo control del monasterio. Este acuerdo es ratificado por una serie de laicos que se identifican como vicarios de los habitantes junto con sus gasalianes (Sáez, 1987: doc. 184).

Este texto descubre la existencia de un espacio de uso compartido por varias comunidades aldeanas. Todo hace pensar en un área de usos mancomunados, sobre todo destinados al pasto del ganado y a la recolección de leña, bajo gestión de una comunidad supralocal, pero cuyo control había asumido el monarca en algún momento previo a 917, posiblemente como parte de ese nuevo dominio político que se expresaba de esta manera en un ámbito local que no había sido directamente objeto de repoblación. De esa manera surge con claridad en qué consistía el dominio regio, la serna que se desplegaba sobre el monte de Pardominos: la clave era el control de acceso a un espacio comunal. Pero los habitantes del entorno parecen resistirse a que el área de uso comunal se convierta en un espacio de uso exclusivamente monástico. Y es así como estalla el conflicto, el cual finalmente se resuelve a través de la repartición del monte en dos áreas. En realidad, lo que se está repartiendo son los derechos de aprovechamiento... pero no el dominio como tal que sigue estando en manos de los monjes. En definitiva, el caso de Pardominos plasma cómo el rey pudo hacerse con el control del acceso a los comunales como un elemento relevante de su afirmación política. Un derecho que no duda en traspasar a un monasterio que patrocina, con el objetivo de crear una institución a nivel local que sirva para hacer efectivo su poder. Una situación que desencadenó un fuerte conflicto con los habitantes de la zona y que se solventó con importantes cambios en la organización de las comunidades campesinas, que debieron modificar sus prácticas.

Llegados a este punto, resulta necesario plantear una serie de reflexiones que puedan servir para la discusión. Este recorrido a lo largo de cinco siglos sirve para destacar la extremada variabilidad de las situaciones, que se van transformando a lo largo de todo el periodo. Pero en general puede decirse que en la cuenca del Duero la gestión directa de la producción formó parte de la organización campesina. Fueron los campesinos quienes se encargaron de su gestión. Sin embargo, entre los siglos V al VII, surgió un dominio político que se basaba en la identificación de la autoridad central con las elites locales. Estas no disponían, al menos en el sector suroccidental de la cuenca del Duero, de una gran propiedad. La desaparición del orden político imperial permitió a los grupos que ejercían el dominio local, situados en un segundo o tercer escalón del poder, cobrar un especial protagonismo. Se hicieron con los mecanismos políticos a escala local y ejercieron un control externo de procesos productivos que dominaban gracias a la tributación. Aunque carecemos de datos, hay que sospechar que esa actividad debió influir en la propia organización campesina, como parece comprobarse gracias a la detección de pizarras numerales en asentamientos rurales. Pero se trataba de un dominio político que dependía en gran medida de la vinculación con un referente político. Cuando este desapareció en el 
siglo VIII se produjo un colapso en el sistema, que afectó sobre todo a las elites, pero no necesariamente a las comunidades campesinas. Como consecuencia, es muy posible que estas mantuvieran una articulación de los paisajes y espacios productivos ajena al control de cualquier entidad externa. El análisis de la Sierra de Ávila, a partir de la localización de las tumbas excavadas en roca y de los testimonios palinológicos evoca una evolución de esta naturaleza, con un paisaje creado y gestionado desde las comunidades que parece perpetuarse, en sus líneas principales, desde el siglo VI hasta el XII. Una clave de esa resiliencia debió ser la organización de áreas de uso comunal, que garantizaban recursos y generaban una sólida identidad, agrupando a veces a varias comunidades emplazadas en un mismo marco territorial.

Sin embargo, la progresiva afirmación del poder político asturiano, gracias a la expansión territorial, desde mediados del siglo IX va a generar una serie de modificaciones. Una vía para implementar ese nuevo poder fue el control de un dominio superior que incluía el control de acceso a los comunales. Inicialmente son los monarcas quienes dispusieron de esa potestad, pero, a fin de consolidar las redes políticas existentes, cedieron tales derechos. Por otro lado, los nuevos dominadores se hicieron con parcelas agroganaderas, cuya posesión se justificó gracias la actuación de los reyes. Todo ello repercutió en la organización de las comunidades que vieron disminuida su autonomía y sufrieron una intervención directa sobre los espacios y procesos productivos. Una situación que partió de un hecho político y de dominio.

En términos más teóricos, la cuenca del Duero a lo largo de los siglos $\mathrm{V}$ al $\mathrm{X}$ muestra claros indicios de la presencia de sociedades de base campesina, tal y como las ha definido Chris Wickham, aunque eso no implica en absoluto la inexistencia de lógicas aristocráticas. La escasez de datos que evidencien circuitos comerciales de rango suprarregional, la pobre inversión monumental o la refracción del registro escrito serían indicios de la debilidad del poder elitista durante este periodo. Un poder elitista que solo se podía sostener a través de la presencia de un poder central que pudiera reafirmar el estatus de estos individuos por encima de la comunidad y legitimar, de esa manera, la extracción de un excedente en términos "políticos". No obstante, la afirmación del poder asturiano conllevó nuevas dinámicas que permitieron la consolidación de nuevas estructuras políticas, gracias a la afirmación de aristocracias estrechamente ligadas a la monarquía. Como ha señalado Carlos Astarita, una de las principales claves para que las elites pudieran imponer su dominio en estas sociedades fue el control de la redistribución de los recursos. Así se hizo con las sernas y con los espacios comunales, de suerte que el nuevo poder político se convirtió en el garante de esos recursos y de su correcta gestión. Pero rápidamente pasaron a formar parte del stock de bienes que podían usarse para generar políticas de patronazgo con los grupos aristocráticos. Y también se beneficiaron de esta política notables locales que tenían como función el control local de estos bienes o que poseían el control sobre esos recursos de antemano, los cuales sirvieron para negociar su integración en la estructura política asturleonesa, como ocurrió con Gratón.

\section{FUENTES}

Cavero Domínguez, G. y Martín López, E. (1999).Colección documental de la catedral de Astorga, I (646-1126). León: Centro de Estudios San Isidoro e Investigación San Isidoro

David, P. (1947). Études historiques sur la Galice et le Portugal du VIe au XIIe siècle. Lisboa-París: Portugália-Les Belles Lettres

Díaz y Díaz, M. C. (1974).La Vida de San Fructuoso de Braga. Estudio y edición critica. Braga: s.n

Díaz y Díaz, M. C. (2006).Valerio del Bierzo. Su persona. Su obra. León: Centro de Estudios e Investigación San Isidoro

Fernández Flórez, J. A. y Serna Serna, S. (2017).El Becerro Gótico de Cardeña. El primer gran cartulario hispánico (1086). Burgos: Instituto Castellano y Leonés de la Lengua

Juan de Bíclaro (1894). Chronica, en Mommsen, Theodor (ed.). Monumenta Germanica Historica. Auctores Antiquissimi, XI. Chronica Minora II (pp. 211-220). Berlín: Societas Aperiendis Fontibus Rerum Germanicarum Medii Aevii 
Mínguez, J. M.a (1976).Colección Diplomática del Monasterio de Sahagún (siglos IX y X). León: Centro de Estudios e Investigación San Isidoro

Ruiz Asencio, J. M. y Ruiz Albi, I. (2007).Colección documental del Monasterio de San Pedro de Eslonza. Vol. I (912-1300). León: Centro de Estudios e Investigación San Isidoro

Sáez, E. (1987).Colección documental del archivo de la Catedral de León (775-1230). Vol. I (775-952). León: Centro de Estudios e Investigación San Isidoro

Serrano, L. (1925).Cartulario de San Pedro de Arlanza, antiguo monasterio benedictino. Madrid: Centro de Estudios Históricos

Velázquez Soriano, I. (2004).Las pizarras visigodas (Entre el latín y su disgregación. La lengua hablada en Hispania, siglos VI-VII). Burgos: Instituto Castellano y Leonés de la Lengua

Zabalza Duque, M. (1995): Colección diplomática de los Condes de Castilla. Valladolid: Junta de Castilla y León

\section{BIBLIOGRAFÍA}

Ariño, E. (2013). "El hábitat rural en la península ibérica entre finales del siglo IV y principios del VIII: un ensayo interpretativo". Antiquité Tardive, 21, 93-123

Barbero, A. y Vigil, M. (1978). La formación del feudalismo en la Península Ibérica. Barcelona: Crítica

Barrios García, Á. (1985). "Repoblación de la zona meridional del Duero. Fases de ocupación, procedencias y distribución espacial de los grupos repobladores". Studia Historica. Historia Medieval III, 33-82

Blanco González, A. et alii (2015). "Medieval landscapes in the Spanish Central System (450-1350): a paleoenvironmental and historical perspective", Journal of Medieval Iberian Studies, 7:1, 1-17

Botella Pombo, E. (1998). La serna: ocupación, organización y explotación del espacio en la Edad Media (800-1250). Santander: Tantín

Carvajal Castro, Á. (2015). “The monarchy and the elites in early medieval León (ninth-eleventh centuries)”.Journal of Medieval Iberian Studies, 7:2, 232-248

Carvajal Castro, Á (2017). Bajo la máscara del regnum. La monarquia asturleonesa en León (854-1037). Madrid: CSIC

Carvajal Castro, Á. (2017). "Prácticas colectivas y gestión de los espacios agrarios en la Alta Edad Media: una perspectiva comparada desde Irlanda y el noroeste de la Península Ibérica”..Historia Agraria, 73, 162-170

Castellanos. S. y Martín Viso, I. (2005). "The local articulation of central power in the north of the Iberian Peninsula (500-1000). Early Medieval Europe, 13:1, 1-42

Castellanos, S. y Martín Viso, I. (eds.) (2008). De Roma a los bárbaros. Poder central y horizontes locales en la cuenca del Duero. León: Universidad de León

Catalán, R., Fuentes, P. y Sastre, J. C. (2014). Las fortificaciones en la tardoantigüedad. Elites y articulación del territorio (siglos V-VIII d.C.). Madrid: La Ergástula

Chavarría Arnau, A. (2004-2005). "Romanos y visigodos en el valle del Duero (siglos V-VII)”. Lancia, 6, 187-204

Díaz, P. C. (2011). El reino suevo (411-586). Madrid: Akal

Díaz, P. C. y Martín Viso, I. (eds.) (2011). Between taxation and rent. Fiscal problems from Late Antiquity to Early Middle Ages.Bari: Edipuglia

Díez Herrera, C. (1999). "La organización social del espacio entre la Cordillera Cantábrica y el Duero en los siglos VIII al XI: una propuesta de análisis como sociedad de frontera”. En J. Á. García de Cortázar (ed.). Del Cantábrico al Duero. Trece estudios sobre organización social del espacio en los siglos VIII a XIII (pp. 123-155). Santander: Universidad de Cantabria

Escalona, J. (2002). Sociedad y Territorio en la Alta Edad Media Castellana. La formación del Alfoz de Lara. Oxford, Archaeopress

Escalona, J. (2016). "In the name of a distant king: representing royal authority in the county of Castile, c. 900-1038". Early Medieval Europe, 24:1, 74-102 
Escalona, J. yReynolds, A. (eds.) (2011).Scale and Scale Change in the Early Middle Ages. Exploring Landscape, Local Society and the World Beyond. Turnhout: Brepols

Espinosa Ruiz, U. y Castellanos, S. (eds.) (2006). Comunidades locales y dinámicas de poder en el norte de la península ibérica durante la Antigüedad Tardía. Logroño: Universidad de La Rioja

Estepa Díez, C. (1984). "El alfoz castellano en los siglos IX a XII". En Estudios dedicados al profesor D. Angel Ferrari Núñez. En la España Medieval IV (pp. 305-341). Madrid: Universidad Complutense de Madrid, II

Estepa Díez, C. (1992). “Configuración y primera expansión del reino astur. Siglos VIII y IX”. En F. J. Lomas y F. Devís (eds.). De Constantino a Carlomagno. Disidentes, heterodoxos, marginados (pp. 179-195). Cádiz: Universidad de Cádiz

Fernández, D. (2017). Aristocrats and statehood in Western Iberia, 300-600 C.E. Philadelphia: University of Pennsilvania Press

García de Cortázar, J. Á. (1985). “Del Cantábrico al Duero”. En J. Á. García de Cortázar y otros (eds.). Organización social del espacio en la España medieval. La Corona de Castilla en los siglos VIII a XV (pp. 43-83). Madrid: Ariel

García Lobo, V. y Cavero Domínguez, G. (2013). San Miguel de Escalada (913-2013). León: Universidad de León

García Moreno, L. A. y Vigil-Escalera, A. (eds.) (2011). 711. Arqueología e historia entre dos mundos. Madrid: Museo Arqueológico Regional

Gutiérrez González, J. A. (1995): Fortificaciones y feudalismo en el origen y formación del reino leonés (siglos IX-XIII). Valladolid: Universidad de Valladolid

Gutiérrez González, J. A. (2013a). “Oviedo y el territorio astur entre Mahoma y Carlomagno (siglos VII-IX). El poder del pasado en el origen del reino de Asturias”. En De Mahoma a Carlomagno: los primeros tiempos (siglos VII-IX) (pp. 377-434). Pamplona: Gobierno de Navarra

Gutiérrez González, J. A. (2013b). "Poblamiento de los siglos VII-VIII y conquista musulmana del antiguo Conventus Asturum”. En X. Ballestín y E. Pastor (eds.). Lo que vino de Oriente. Horizontes, praxis y dimensión material de los sistemas de dominación fiscal en al-Andalus (ss. VII-IX) (pp. 102-121). Oxford: Archaeopress

Isla Frez, A. (2010). Ejército, sociedad y politica en la peninsula ibérica entre los siglos VII y XI. Madrid: CSIC

López Quiroga, J. (2004). El final de la Antigüedad en la Gallaecia. La transformación de las estructuras de poblamiento entre Miño y Duero (siglos $V$ al X). La Coruña: Fundación Pedro Barrié de la Maza

Martín Viso, I. (2002). Fragmentos del Leviatán. La articulación politica del espacio zamorano en la Alta Edad Media. Zamora: Instituto de Estudios Zamoranos Florián de Ocampo

Martín Viso, I. (2007): “La sociedad rural en el suroeste de la Meseta del Duero (siglos VI-VII)”. En G. del Ser Quijano e I Martín Viso (eds.). Espacios de poder y formas sociales en la Edad Media (pp. 171-188). Salamanca: Ediciones Universidad de Salamanca

Martín Viso, I. (ed.) (2009). ¿Tiempos oscuros? Territorio y sociedad en el centro de la península ibérica (siglos VII-X). Madrid: Sílex

Martín Viso, I. (2013).“The Visigothic Slates and their archaeological contexts”. Journal of Medieval Iberian Studies, 5:2, 145-168

Martín Viso, I. (2016): “Colapso político y sociedades locales: el Noroeste de la península ibérica (siglos VIII-IX)”. Reti Medievali. Rivista, 17:2, 335-369

Martínez Sopena, P. (1985). La Tierra de Campos Occidental. Poblamiento, poder y comunidad del siglo X al XIII. Valladolid: Diputación de Valladolid

Mínguez, J. Ma (2004)."En torno a la génesis de las sociedades peninsulares altomedievales. Reflexiones y nuevas propuestas”. Studia Historica. Historia Medieval, 22, 169-188

Mínguez, J. Ma (2009). “Poderes locales en el espacio central leonés durante el periodo astur”. En F. J. Fernández Conde y C. García de Castro Valdés (eds.). Poder y simbología en Europa. Siglos VIII-X (pp. 199-214). Gijón: Trea

Pastor Díaz de Garayo, E. (1996). Castilla en el tránsito de la antigüedad al feudalismo. Poblamiento, poder político y estructura social del Arlanza al Duero (siglos VIII-XI).Valladolid: Junta de Castilla y León 
Portass, R. (2017). The Village World of Early Medieval Northern Spain. Local Community and the Land Market. Woodbrige: The Boydell Press

Quirós Castillo, J. A. (2011). "Early medieval landscapes in North-West Spain: local powers and communities, fifthtenth centuries". Early Medieval Europe, 19:3, 285-311

Quirós Castillo, J. A. (ed.) (2013). El poblamiento rural de época visigoda en Hispania. Arqueología del campesinado en el interior peninsular. Bilbao: Universidad del País Vasco, 2013

Quirós Castillo, J. A. (ed.) (2016). Archaeology of Social Inequality in Northwestern Iberia during the Early Medieval period. Oxford, Archaeopress

Quirós Castillo, J. A. y Castellanos, S. (dirs.) (2015). Identidad y etnicidad en Hispania. Propuestas teóricas y cultura material en los siglos V-VIII. Bilbao: Universidad del País Vasco

Quiro\#s Castillo, J. A. y Tejado Sebastián, J. Ma (coords.) (2012). Los castillos altomedievales en el noroeste de la Peni\#nsula Ibérica. Bilbao: Universidad del País Vasco

Sánchez-Albornoz, C. (1966): Despoblación y repoblación del Valle del Duero. Buenos Aires: Instituto de Historia

Santos Salazar, I. (2013). "Los privilegios de Barrio y Berbeia: elites, memoria y poder en Lantarón durante el siglo X”. Studia Histórica. Historia Medieval, 31, 51-81

Tejerizo García, C. (2017). Arqueología de las sociedades campesinas en la cuenca del Duero durante la Primera Alta Edad Media. Bilbao: Universidad del País Vasco, 2017

Tente, C. (2012). "Settlement and territory in the Upper Mondego Basin (Centre of Portugal) between the 5th century and the 11th century". Archeologia Medievale, XXXIX, 385-398

Vigil-Escalera Guirado, A. (2015). Los primeros paisajes altomedievales en el interior de Hispania. Registros campesinos del siglo quinto d.C. Bilbao: Universidad del País Vasco

VV. AA. (2002). La época de la monarquía asturiana. Oviedo: Real Instituto de Estudios Asturianos

\section{Notas}

* Este trabajo se ha realizado dentro del proyecto HAR2016-76094-C4-4-R. Se basa en la conferencia ofrecida en el marco de las IV Jornadas de Jóvenes Investigadores sobre las Sociedades precapitalistas, pronunciada el 5 de septiembre de 2017 en la Universidad de La Plata (Argentina). Se ha conservado el texto y se han añadido algunas referencias a las fuentes utilizadas, prescindiendo del aparato bibliográfico, aunque se ha añadido una bibliografía básica final con las principales obras. Agradezco a la profesora Rosana Vassallo su invitación, así como a los participantes de dicho encuentro por el intercambio de cuestiones que permitieron mejorar la propuesta original. 